This item was submitted to Loughborough's Research Repository by the author.

Items in Figshare are protected by copyright, with all rights reserved, unless otherwise indicated.

\title{
Removal of hazardous material from wastewater by using metal organic framework (MOF) embedded polymeric membranes
}

PLEASE CITE THE PUBLISHED VERSION

https://doi.org/10.1080/01496395.2018.1508232

\section{PUBLISHER}

(C) Taylor \& Francis

\section{VERSION}

AM (Accepted Manuscript)

\section{PUBLISHER STATEMENT}

This is an Accepted Manuscript of an article published by Taylor \& Francis in Separation Science and Technology on 25 September 2018, available online:

http://www.tandfonline.com/10.1080/01496395.2018.1508232.

\section{LICENCE}

CC BY-NC-ND 4.0

\section{REPOSITORY RECORD}

Gnanasekaran, Gnanaselvan, Sasikumar Balaguru, G. Arthanareeswaran, and Diganta Bhusan Das. 2018. "Removal of Hazardous Material from Wastewater by Using Metal Organic Framework (MOF) Embedded Polymeric Membranes". figshare. https://hdl.handle.net/2134/36236. 


\title{
Removal of Hazardous Material from Wastewater by using Metal Organic Framework (MOFs) Embedded Polymeric Membranes
}

\author{
Gnanaselvan Gnanasekaran ${ }^{\mathrm{a}}$, Sasikumar Balaguru ${ }^{\mathrm{a}}$, Arthanareeswaran Gangasalam*, \\ Diganta B Das ${ }^{b}$ \\ ${ }^{\mathrm{a}}$ Membrane Research Laboratory, Department of Chemical Engineering, National Institute of \\ Technology, Tiruchirappalli, Tamil Nadu, India. PIN-620015. \\ ${ }^{b}$ Department of Chemical Engineering, Loughborough University, Loughborough, UK \\ Email.id: arthanaree10@yahoo.com
}

\begin{abstract}
Heavy metals in wastewater can cause acute and chronic toxicity which leads to learning disabilities, cancer, and even death. In present work, Zn based MOF (MOF-5) was prepared, and it is characterized by FT-IR, XRD, and SEM Analysis. MOF-5 incorporated polymeric membranes (PES, CA and PVDF) prepared by phase inversion method. The morphology, hydrophilicity, porosity, permeation performance, antifouling properties and the rejection of $\mathrm{Cu}$ (II) and $\mathrm{Co}$ (II) metal ions of the membranes were significantly improved with the addition MOF-5. Higher rejection efficiency for Co (II) in PES/MOF-5 and CA/MOF-5 was found to be $74.40 \%$ and $77 \%$ respectively.
\end{abstract}

Keywords: Heavy metal ions, Metal-organic frameworks (MOFs), Composite membranes, Nanofiltration (NF). 


\section{Introduction}

Increasing contamination of indsutrial wastewater by heavy metal ions found to be significant global concern. The primary source of heavy metal ions are industries like electroplating, battery manufacturing, metallurgical, tannery, and metal finishing. ${ }^{[1,2]}$ Unlike organic contaminants, heavy metal ions are non-biodegradable in nature and likely to cause healthy risk by entering into the human food chain through marine animals. ${ }^{[3,4]}$ Over the years, numerous techniques have been studied for the removal of heavy metal from wastewater namely adsorption, precipitation, ion exchange, membrane separation, electro dialysis, and photocatalysis. ${ }^{[5]}$ Nanofiltration (NF) membrane was proven to be a very potential method for removal of heavy metals because of its low cost and high effectiveness. ${ }^{[6]}$ A comparative study of copper and cadmium removal from wastewater using NF has been investigated. ${ }^{[7]} \mathrm{NF}$ membranes were shown to be capable of removing $96 \%$ of copper and $97 \%$ of cadmium ions. However, the difficulties to achieve both high water permeability and rejection simultaneously limits the performance of NF membranes.

Metal-organic frameworks (MOFs) are proven to be a promising material to overcome the above mentioned drawback. MOFs offers highly tunable pore structure, along with an enormous variability and chemical functionality. ${ }^{[8]}$ MOFs can be synthesised by combination of metallic and organic linkers namely benzenedicarboxylates (BDC) and benzetricarboxylates (BTC) via chemical or physical techniques. The incorporation of MOFs on polymer matrix has been reported for the removal of dye and heavy metals using nanofiltration. ${ }^{[9,10]}$ Thin film nanocomposite membranes were developed by embedding MOFs on Polyimide support shows increased permeability of solvent due to increase in porosity and hydrophilicity. ${ }^{[9]} \mathrm{UiO}-$ 66@GO/PES composite membranes has been reported with enhanced antifouling property. The pure water flux of MOFs incorporated composite membrane was increased by $351 \%$ 
compared to that of neat PES membrane, together with increased rejection ratio to organic dyes. ${ }^{[1]}$ The MOFs were used for the removal of heavy metal ions from aqueous solution. Bakhtiari ${ }^{[2]}$ and Rivera et al., ${ }^{[12]}$ proven that MOF-5 can be an effective adsorbent for the removal of heavy metal ions like copper and lead from aqueous medium. Therefore, research on MOF embedded polymeric membrane is highly desirable, especially for the application of water purification. ${ }^{[10]}$ Despite these considerable advantages, limited structural stability of MOFs when exposure to water remains a point of concern. The water stability of MOFs related to composition of metal sites and structure of metal clusters. ${ }^{[13]}$ Polymer and MOFs is controlled by weak interactions such as Hydrogen bond, van der Waals forces, and $\pi-\pi$ stacking. MOFs introduces free volume and active porous sites on the membrane will be favourable for gas and liquid separation. ${ }^{[14]}$ Herein, we report MOF-5 embedded membranes with three different polymers namely Cellulose acetate (CA), Polyethersulfone (PES), and Polyvinylidene fluoride (PVDF). MOF-5, a prototypical Zn based MOF with cubical structure have been used to achieve the high water purification performance for the removal of copper and cobalt ions (hazardous materials) from wastewater. The schematic representation of removal of heavy metal ion from aqueous solution by MOF-5 incorporated polymeric membranes Nanofiltration is shown in Scheme. 1.

\section{Experimental}

\section{Materials}

N, N-dimethylformamide (DMF, Merck), Terephthalic acid (SRL Pvt Ltd., India), Zinc nitrate hexahydrate (Loba Chemie Pvt Ltd. India) were employed to prepare the MOF material. All chemicals used were of analytical grade. Copper sulphate pentahydrate $\left(\mathrm{CuSO}_{4} .5 \mathrm{H}_{2} \mathrm{O}\right)$, Cobalt sulfate hexahydrate $\left(\mathrm{CoSO}_{4} .7 \mathrm{H}_{2} \mathrm{O}\right)$ were purchased from Merck specialties Pvt Ltd., India. Polyethersulfone (PES, veradel 13000 p), Polyvinylidene fluoride (PVDF, Solef® 6010) was procured from Solvay Solexis Ltd., India. Cellulose Acetate (CA) were purchased from Mysore 
84 Acetate and Chemicals Company Ltd., India. Ultrapure water was produced in the laboratory using millipore pilot plant.

\section{Preparation and characterization of MOF-5}

MOF-5 was synthesized in a glass reactor equipped with reflux condenser following the procedure reported in the literature. ${ }^{[9,15]} 2 \mathrm{~g}$ of terephthalic acid and $9.31 \mathrm{~g}$ of zinc nitrate hexahydrate were dissolved in $60 \mathrm{ml}$ of DMF solution under stirring at atmospheric conditions and heated up to $150^{\circ} \mathrm{C}$ for $4 \mathrm{~h}$. After $2 \mathrm{hr}$, white crystals of MOF-5 was formed, and the product was cooled down to room temperature. The white crystals were separated by filtration and washed with $100 \mathrm{ml}$ acetone, and finally, solid crystals were dried at $60^{\circ} \mathrm{C}$ for $3 \mathrm{hr}$ in a vacuum oven. Fourier transform infrared (FTIR) spectroscopy of MOF-5 (Thermo Scientific Nicolet iS5 FT-IR spectrometer) was analysed in the spectral region of wavenumbers from 400 to 4000 $\mathrm{cm}^{-1}$. The crystalline structure of MOF-5 was studied using X-ray diffractometer (Model Rigaku Ultima III) using a monochromatic source of $\mathrm{Cu} \mathrm{K} \alpha$ radiation with the range of $2 \Theta$ with an angle of $5^{\circ}$ to $80^{\circ}$ and with an operating voltage of $40 \mathrm{kV}$. The surface morphology of prepared MOF-5 was studied using Scanning Electron Microscope equipped with Energy Dispersive X-ray (Quanta 250 FEG).

\section{Fabrication of MOF incorporated polymeric membranes}

The neat and MOF-5 embedded PES, CA, PVDF membranes were prepared by phase inversion induced by immersion precipitation method. ${ }^{[8]} \mathrm{MOF}-5$ loading was kept at $0.5 \%$ of the polymers. The casting solutions contain $17.5 \%$ of polymers (PES, CA, and PVDF) and 21.7 $\mathrm{ml}$ of DMF solvent. The composition of casting solutions for all the membranes is shown in Table 1 . MOF-5 (0.5\%) was added into $21.7 \mathrm{ml}$ of DMF and dispersed well by sonication for 1 hr to improve the homogeneity using Ultrasonicator. After dispersing MOF-5 in DMF, polymers were dissolved in the dope solution by mechanical stirring for about $3 \mathrm{hr}$. The 
complete dispersion of Polymer/MOF-5 was again confirmed using ultrasonication for $30 \mathrm{~min}$ before casting. After removing air bubbles, homogenous casting solution was cast onto a finely levelled glass plate with $400 \mu \mathrm{m}$ thickness. Subsequently, the film was then immersed in the distilled water which is maintained at $10^{\circ} \mathrm{C}$, and then membranes were soaked in fresh distilled water for $24 \mathrm{hr}$ to ensure the complete phase inversion.

\section{Membrane Characterisation}

The functional group of neat and MOF-5 incorporated polymeric membranes (PES, CA and PVDF) were investigated by ATR interfaced Fourier transform infrared (FTIR) spectrophotometer (Thermo Scientific Nicolet iS5 FT-IR spectrometer, India). The range of wavenumbers were analysed between 400 to $4000 \mathrm{~cm}^{-1}$. The XRD pattern of membranes were analysed by X-ray diffractometer (Model Rigaku Ultima III) using a monochromatic source of $\mathrm{Cu} \mathrm{K} \alpha$ radiation with the range of $2 \Theta$ with an angle of $5^{\circ}$ to $80^{\circ}$ and with an operating voltage of $40 \mathrm{kV}$.The surface morphology of neat polymer and composite Polymer/MOF-5 membranes were studied using Scanning Electron Microscope equipped with Energy Dispersive X-ray (VEGA 3, TESCAN, USA). The membrane samples were fractured in liquid nitrogen, and gold coated by sputtering to make them conductive. The MOF-5 distribution on the surface of the composite membrane has been analysed by Energy Dispersion of X-ray (EDX).

Hydrophilicity of membranes were measured using contact angle measurement. Goniometer (model 250-F1 Rame-Hart Instruments, Succasunna, NJ) used for the determination of Contact angle for membranes by sessile drop method using. About $5 \mu \mathrm{L}$ drop of water is injected on a dry membrane surface at five different locations through a micro syringe. The average of contact angle value was measured from the individual droplets in the five regions which determine the hydrophilicity of membrane.

\section{Permeation and rejection studies}


The permeability of neat and MOF-5 incorporated polymeric membranes were studied by using pure distilled water and aqueous solutions of $\mathrm{Cu}$ (II), $\mathrm{Co}$ (II) at a concentration of $1000 \mathrm{ppm}$. The permeation studies were conducted by using a dead end stirred NF cell with an active membrane area of $14.6 \mathrm{~cm}^{2}$. The water was pressurized by supplying nitrogen gas to the NF cell, and then membranes were compacted for $30 \mathrm{~min}$ at 10 bar pressure to minimize the compaction effects. At steady state conditions, the water permeated for $10 \mathrm{~min}$ at $25^{\circ} \mathrm{C}$ were noted down, and the permeate flux $\left(\mathrm{J}_{\mathrm{w}}\right)$ of each membrane was quantified based on the following Eq. (1).

$$
J_{w}=\frac{\mathrm{V}}{\mathrm{A} \times \Delta \mathrm{t}}
$$

where $J_{\mathrm{w}}$ is the permeate flux $\left(\mathrm{kg} / \mathrm{m}^{2} \mathrm{hr}\right), \mathrm{V}$ is permeate volume $\left(\mathrm{m}^{3}\right), \mathrm{A}$ is effective membrane area $\left(\mathrm{m}^{2}\right)$, and $\Delta \mathrm{t}$ is permeation time $(\mathrm{hr})$.

The performance of neat and composite membranes was evaluated using percentage rejection of heavy metal ions from aqueous medium. The concentration of permeate solutions was determined by using Atomic absorption spectrophotometer (Perkin Elmer, Analyst 4000, USA). The measured value of permeate $\left(C_{p}\right)$ and feed concentration $\left(C_{f}\right)$ was used to calculate observed rejection percentage ( $\mathrm{R}_{\mathrm{obs}} \%$ ) by following the Eq. (2).

$$
\mathrm{R}_{\mathrm{obs}}(\%)=\left(1-\frac{\mathrm{C}_{\mathrm{p}}}{\mathrm{C}_{\mathrm{f}}}\right) \times 100
$$

\section{Membrane Resistance $\left(\boldsymbol{R}_{m}\right)$}

The resistance to the feed flow of neat and MOF-5 incorporated polymeric membrane has been calculated by Eq. (3).

$$
\mathrm{R}_{\mathrm{m}}=\left(\frac{\Delta \mathrm{P}}{\eta_{\mathrm{w}} \times \mathrm{J}_{\mathrm{w}}}\right)
$$

Where, 
$\Delta \mathrm{P}$ - Transmembrane Pressure.

$\eta_{\mathrm{w}}$ - Viscosity of the feed.

\section{Membrane porosity and pore size}

157 To measure the membranes porosity, samples were cut into specific sizes and then mopped with filter paper. After noting their wet weight, the samples are dried in an oven at $60^{\circ} \mathrm{C}$ for 24 hr. The porosity $(\varepsilon)$ and mean pore radius of the membranes were calculated by [Eqn. 1], and [Eqn. 2] respectively in the Supporting Information.

\section{Determination of Mass Transfer Coefficient and Diffusion Coefficient}

Due to concentration polarisation, the solute concentration at membrane surface $\left(\mathrm{C}_{\mathrm{m}}\right)$ is higher than that of the bulk solution concentration $\left(\mathrm{C}_{\mathrm{f}}\right)$. This leads to additional resistance to the permeate flux $\left(\mathrm{J}_{\mathrm{v}}\right)$, and it can be expressed based on the Concentration Polarisation Model described in the Supporting Information [Eqn. 3]. Correlation for the mass-transfer coefficient can be obtained based on the diffusive transport of the heavy metal ions described in the

Supporting Information [Eqn. 4]. The diffusivity of an aqueous solution of $\mathrm{Cu}$ (II) and $\mathrm{Co}$ (II) was found to be $4.335 \times 10^{-9} \mathrm{~m}^{2} / \mathrm{s}, 4.182 \times 10^{-9} \mathrm{~m}^{2} / \mathrm{s}$ respectively, and listed in Table 2 . Observed rejection efficiency of heavy metal ions were affected by the concentration polarisation, and hence, the real rejection percentage of the membranes can be calculated using the concentration at the surface of the membrane $\left(\mathrm{C}_{\mathrm{m}}\right)$ by [Eqn. 6], in the Supporting Information.

\section{Results and Discussion}

\section{FTIR characterization of MOF-5}

174 The FTIR spectra of MOF-5 shown in Fig. 1. Asymmetric stretching of C-O bonded to $\mathrm{Zn}$ has been identified by the attachment of carboxylate ligand to $\mathrm{Zn}_{4} \mathrm{O}$ centre were indicated in the peaks of 1381 And $1573 \mathrm{~cm}^{-1}$. The peak values between the range of 900 to $1250 \mathrm{~cm}^{-1}$ has various small peaks are appeared to indicate the $\mathrm{C}-\mathrm{H}$ stretching of benzene dicarboxylate 
linker. The broad peak occurred in the range of $3161 \mathrm{~cm}^{-1}$ shows the $\mathrm{O}-\mathrm{H}$ group IR bands at 1502, and $653 \mathrm{~cm}^{-1}$ indicated random dimethylformamide (DMF) distribution in the MOF-5 framework structure. ${ }^{[17]}$

\section{XRD analysis of MOF-5}

X-ray diffraction analysis of MOF-5 shown in Fig. 2 . The peaks at $6.8^{\circ}, 9.7^{\circ}, 14^{\circ}$ and $15.8^{\circ}$ in $2 \theta$ which indicates the formation of a crystalline structure. ${ }^{[17]}$ The inconsistency peaks appear due to the framework interpenetration and pore occupation. The intensities of the two peaks were overturned that can be attributed to some alterations of atomic orientations in the crystal planes by absorbed species (solvent and water molecules), unreacted zinc centers and framework interpenetration.

\section{Surface Morphology of MOF-5}

Surface morphology of MOF-5 have shown using SEM images in Fig. 3. Irregularly shaped, the majority had the cubic shape with crystals structure and porous nature, its present in the (Fig. 3a and 3d). ${ }^{[17]}$ The cubical structure has occurred more, and some cluster-like arrangement also present which shows the adsorption property of MOF-5, its shows in the (Fig. $3 \mathrm{~b}$ and $3 \mathrm{c}$ ). The organic cluster and inorganic moiety interaction have occurred in MOF-5.

\section{Energy Dispersive X-ray Spectroscopy of MOF-5}

The elemental composition of the MOF-5 was characterized by EDX (Fig. S1, Supporting Information) revealing the expected elemental constituents $(\mathrm{C}, \mathrm{Zn}$, and $\mathrm{O})$ are detected. The peak appearance indicate the $\mathrm{Zn}$ metal ion attach with carboxylate ligand and it proves the formation of MOF-5 by the interaction of metal ion and organic cluster. ${ }^{[17]}$

\section{FTIR characterisation of membranes}


The FTIR spectra of neat and MOF-5 incorporated polymeric membranes namely PES/MOF-

$\mathrm{CA}$ and PVDF membranes are repeated in composite CA/MOF-5, PES/MOF-5 and PVDF/MOF-5 membrane spectra, in which peaks corresponding to MOF-5 were also observed. The peak values for both neat PES and PES/MOF-5 at 1240, 1485, and $1578 \mathrm{~cm}^{-1}$ have identified the bands of aromatic ether, $\mathrm{C}=\mathrm{C}$ bond stretch and aromatic bands of the benzene ring respectively which confirms the characteristic peaks of PES. The presence of the peak value at $3370 \mathrm{~cm}^{-1}$ in PES/MOF-5 membranes indicates the $(\mathrm{O}-\mathrm{H})$ stretching of MOF-5 in the PES membranes. ${ }^{[18]}$ In case of neat CA and CA/MOF-5 membranes the peak at 1746 $\mathrm{cm}^{-1}$ was identified the stretching of carbonyl group has been present in both membranes and for composite CA/MOF-5 membrane the peak occurred in the range of $3460 \mathrm{~cm}^{-1}$ shows the $\mathrm{O}-\mathrm{H}$ stretching which indicates the presence of MOF-5 in the membranes. ${ }^{[19]}$ Band at wavenumbers $1396 \mathrm{~cm}^{-1}$ and $1175 \mathrm{~cm}^{-1}$ is due to $\mathrm{CH}$ stretching vibration and $\mathrm{C}-\mathrm{F}$ stretching vibration in PVDF and PVDF/MOF-5 membranes. The broad peaks occurred at $3429 \mathrm{~cm}^{-1}$ in FTIR spectra of PVDF/MOF-5 could be assigned to O-H stretching. ${ }^{[20]}$ From these functional group identification, confirms MOF-5 is embedded into membranes and create a polymeric structure as an integral part, could be enhancing the hydrophilic nature compared with neat membranes.

\section{XRD analysis of membranes}

The XRD diffraction patterns of MOF-5, neat and MOF-5 incorporated polymeric membranes were shown in Fig. 5. The XRD spectra of MOF-5 had two peaks at $9.8^{\circ} 2 \theta$ and $15.8^{\circ} 2 \theta$, which confirm the crystallinity of MOF-5 particles. The peak occurrence of little shift at $9.8^{\circ}$ $2 \theta$ in the composite PES/MOF-5, CA/MOF-5 and PVDF/MOF-5 membranes in the dispersion peak of PES, CA and PVDF membranes due to the low addition of MOF-5. It's indicated that the slight interaction between MOF-5 and polymeric membranes. ${ }^{[21]}$ It is confirmed that the 
synthesized MOF-5 improve the stability, hydrophilicity and antifouling properties of composite polymeric/MOF-5 membranes. ${ }^{[21,22]} \mathrm{XRD}$ analysis indicate that the MOF-5 presence in the Polymeric membrane matrix

\section{Surface morphology of membranes}

The surface morphology of the neat and MOF-5 embedded CA, PES, PVDF membranes was monitored by SEM images. The cross-sectional view of neat and modified PES membrane is shown in Fig. 6. It is well known that the skin layer and porous sublayer in the membrane determine the water permeation rate and separation factor. ${ }^{[23]}$ The thick and dense asymmetric structures were observed on neat PES membrane such morphology was responsible for the lower pore radius and membrane permeability. In case of modified PES membrane, the interconnection between skin top layer and substructure (bottom layer) were improved. Fingerlike substructures and thin skin layer were observed. Subsequently, increase in pore radius and decreased macro voids were found with the addition of 0.5 wt. \% of MOF-5.

The asymmetry structure of sponge-like cross-section, finger-like and highly porous structure was observed in the surface morphology of neat CA and CA/MOF-5 in Fig. 7. The MOF-5 has been uniformly dispersed in the polymeric membranes, and the structure of the MOF-5 incorporated membranes does not differ from the neat membranes due to the low-level loading 0.5 wt. $\%$ of MOF-5 into the membranes. Defective pore structure has been occurred due to the interfacial stresses of MOF-5 and membranes. ${ }^{[22]}$ The increase in the pore size indicated the increased hydrophilicity and permeability for CA/MOF-5 which improves the membrane to be a perfect membrane for the removal of heavy metal ions. Fig. 8 shows the cross sectional view of neat PVDF and PVDF/MOF-5 membranes. An asymmetric structure consisting of a dense top layer, a porous sublayer (support), and a sponge-like structure in the bottom layer. It seems that the support layer begins with finger-like cavities underneath the dense top layer ending up in large voids near the bottom layer. In the pristine membrane, a significant portion 
of sublayer is made of a spongy structure consisting of small cellular pores, and only little

251 finger-like voids were observed underneath the top surface. While the addition of $0.5 \mathrm{wt} \% \%$ of MOF-5 into the PVDF casting solution the finger-like voids have been developed nearly up to the membrane bottom, and the share of spongy pores is lower by increasing the hydrophilicity of PVDF membranes. Porosity was enhanced by the addition of MOF-5 in the casting solutions of PVDF membrane. ${ }^{[24]}$ This trend can be interpreted and explained by membrane formation mechanism during phase inversion process into the coagulation bath. MOF-5 in the casting solution increases the penetration of nonsolvent (water) into the casting solution.

\section{Energy Dispersive X-ray Spectroscopy of membranes}

The presence of organic elements in both neat and MOF-5 incorporated Polymeric membranes, indicates that the presence of MOF-5 does not affect the asymmetric membrane structures. The MOF-5 embedded polymeric membranes shows only minor percentage of $\mathrm{Zn}$ elements could be due to the low percentage loading of MOF-5 (Fig. S2, Fig. S3, and Fig. S4, Supporting Information). The presence of $\mathrm{Zn}$ element in the MOF-5 incorporated polymeric membranes confirms the presence of MOF-5 in the polymeric matrix. ${ }^{[25]}$

\section{The Porosity and Average Pore Radius of Membranes}

The porosity and mean pore radius values were shown in Table. 3 . The average pore radius of PES/MOF-5 membrane has been increased from $5.62 \mathrm{~nm}$ to $6.97 \mathrm{~nm}$, and the porosity (\%) value also increase from $70 \%$ to $78 \%$ due to the addition of MOF-5 into the PES casting solution and its obviously shows that MOF-5 has improved the hydrophilicity of PES. ${ }^{[26]}$ The average pore radius of CA/ MOF-5 membrane has been increased from the range of $5.57 \mathrm{~nm}$ to $9.09 \mathrm{~nm}$ due to the addition of MOF-5 which improve the hydrophilicity of CA membranes and porosity (\%) also increased from 72 to $81 \%$. ${ }^{[22]}$ The average pore radius of PVDF/MOF5 has been raised from the range of $3.92 \mathrm{~nm}$ to $4.3 \mathrm{~nm}$ with the addition of MOF-5. ${ }^{[26]}$ 


\section{Hydrophilicity Measurement}

The hydrophilicity of the membranes characterized by the contact angle measurement and the contact angle data are listed in the Table. 4 . The contact angle falls with the addition of MOF5 , and this could be due to fact that contact angle is a function of surface roughness. The contact angle of PES membranes decreased from $86.075^{\circ}$ to $76.42^{\circ}$, with the addition of MOF-5 which shows that the hydrophilicity PES/MOF-5 membranes significantly superior to neat PES membranes. ${ }^{[27]}$ In case of CA, PVDF membranes contact angle was decreased from $75.03^{\circ}$ to $70.68^{\circ}$ and $80.47^{\circ}$ to $72.975^{\circ}$ respectively, which proves that hydrophilicity has been increased because of the addition of MOF-5. ${ }^{[19,24]}$

\section{Membrane Resistance and Permeability}

The pure water flux of neat and MOF-5 embedded PES, CA and PVDF membranes can be used to determine the hydraulic permeability and membrane resistance. The pure water flux of neat and MOF-5 incorporated polymeric membranes is shown in Fig. 9. The membrane permeability is inversely proportional to the membrane resistance. The membrane permeability and membrane resistance was calculated from Eq. (1), and Eq. (3) respectively and listed in Table.5. The neat PES, CA and PVDF membranes were having higher membrane resistance compared with PES/MOF-5, CA/MOF-5 and PVDF/MOF-5 could be due to the increase in hydrophilicity of membranes by addition of MOF-5. ${ }^{[27]}$ For PES membrane, the permeability has been increased from $29.52 \pm 1.6 \mathrm{~L} / \mathrm{m}^{2} \mathrm{hr}$ to $53.31 \pm 1.6 \mathrm{~L} / \mathrm{m}^{2} \mathrm{hr}$ and consequently membrane resistance was decreased from $13 \times 10^{13} \mathrm{~m}^{-1}$ to $7.4 \times 10^{13} \mathrm{~m}^{-1}$. In case of CA/MOF-5 permeability was increased from $41.01 \pm 1.2 \mathrm{~L} / \mathrm{m}^{2} \mathrm{hr}$ to $69.72 \pm 1.4 \mathrm{~L} / \mathrm{m}^{2} \mathrm{hr}$ and the hydraulic resistance was reduced from $9.6 \times 10^{13} \mathrm{~m}^{-1}$ to $5.6 \times 10^{13} \mathrm{~m}^{-1}$ which indicates that the hydrophilicity of CA/MOF-5 membrane has been improved. ${ }^{[19,22]}$ The PVDF/MOF-5 have higher water flux compared to neat PVDF membrane, and hydraulic resistance value was 
reduced from $17 \times 10^{13} \mathrm{~m}^{-1}$ to $11 \times 10^{13} \mathrm{~m}^{-1}$. ${ }^{[24]} \mathrm{CA} / \mathrm{MOF}-5$ has shown higher water flux compared to all other membranes, possibly due to the higher porosity of the CA membranes as observed in Table 3. In all cases, MOF-5 incorporated membranes exhibited higher fluxes than their corresponding neat membranes. The addition of MOF-5 particles to membranes enhances the pure water flux through them, due to the increased hydrophilic character of the membranes. Increase in hydrophilicity could be due to the higher affinity of metal cluster of MOFs for water and consequently the pure water flux also increased.

\section{Heavy Metal Ions Permeability of Membranes}

Experiments were carried out for the removal of copper $\mathrm{Cu}$ (II) and cobalt Co (II) metal ions from water to study the influence of MOF-5. Fig. 10 and Fig. 11 illustrates the variation of the rejection of neat and composite MOF-5 membranes for the metal ion aqueous solutions containing $\mathrm{Cu}$ (II) and $\mathrm{Co}$ (II) respectively. CA/MOF-5, PES/MOF-5, and PVDF/MOF-5 membranes has higher permeability flux of $59 \pm 1.2 \mathrm{~L} / \mathrm{m}^{2} \mathrm{hr}, 41 \pm 1.6 \mathrm{~L} / \mathrm{m}^{2} \mathrm{hr}$ and $27 \pm 1.4 \mathrm{~L} / \mathrm{m}^{2}$ hr respectively for $\mathrm{Cu}(\mathrm{II})$ solution when compared to neat $\mathrm{CA}$, PES, and PVDF membranes. In case of Co (II) solutions, similar higher permeability flux of $47 \pm 1.2 \mathrm{~L} / \mathrm{m}^{2} \mathrm{hr}, 40 \pm 1.4 \mathrm{~L} / \mathrm{m}^{2} \mathrm{hr}$ and $24 \pm 1.2 \mathrm{~L} / \mathrm{m}^{2} \mathrm{hr}$ observed for MOF-5 blend polymeric membranes CA/MOF-5, PES/MOF5, and PVDF/MOF-5 respectively, which proves that the MOF-5 enhance the hydrophilicity and reducing the fouling flux. ${ }^{[28,29]} \mathrm{CA} / \mathrm{MOF}-5$ membranes has higher permeability compared with all other membranes.

\section{Performance of Composite Polymer/MOF-5 Membranes on heavy Metal ion rejection}

The effect of MOF-5 on the percentage rejection of metal ions for membranes is shown in Table 6. The rejection capability of the prepared composite PES/MOF-5, CA/MOF-5 PVDF/MOF-5 membranes was comparatively higher than the neat membranes. The observed rejection of $\mathrm{Cu}$ (II) in neat $\mathrm{CA}$ and $\mathrm{CA} / \mathrm{MOF}-5$ is found to be $50.8 \%$ and $53.3 \%$ respectively. 
322 For PVDF and PVDF/MOF-5 observed rejection was 54.3\% and 52.3\%. The highest observed rejection of $\mathrm{Cu}$ (II) is obtained in $\mathrm{CA} / \mathrm{MOF}-5$ membranes which is due to the higher affinity of MOF-5 with the CA membrane. The Co (II) rejection is shown in Table.7. Rejection performance of prepared membranes for $\mathrm{Co}$ (II) is much higher than that of $\mathrm{Cu}$ (II).Higher rejection efficiency for Co (II) in PES/MOF-5 and CA/MOF-5 was found to be $74.40 \%$ and $77.0 \%$ respectively, which shows that membranes selectivity was not compromised with that of the flux. Hence both the rejection and the permeability flux of composite PES/MOF-5, CA/MOF-5, and PVDF/MOF-5 membranes remains higher than those of the neat polymeric membranes. ${ }^{[27]}$ The real rejection efficiencies $\left(\mathrm{R}_{\text {real }}\right)$ of the heavy metal ions were calculated for both neat and Composite PES/MOF-5, CA/MOF-5, and PVDF/MOF-5 membranes. It was implied that $\mathrm{R}_{\text {real }}$ values of both neat and Composite PES/MOF-5, CA/MOF-5, and PVDF/MOF-5 membranes, remained higher than the $\mathrm{R}_{\mathrm{obs}}$ values. ${ }^{[28]}$ This is due to concentration polarisation, and it remains higher for dead-end NF cell.

\section{Conclusion}

The MOF-5 synthesized by simple Solvothermal method and characterised by FTIR, XRD analysis, SEM with EDX. Surface morphology reveals the formation of cubical structure of MOF-5 and its useful properties for the removal of heavy metal ions from wastewater. The MOF-5 particles incorporated into the three different polymers namely PES, CA and PVDF. The addition of MOF-5 in polymeric membranes influenced porosity and surface mean pore size of the prepared composite membranes. Further, the hydrophilic properties and performance of composite membranes enhanced by the incorporation of MOF-5 due to the metal clusters of MOF-5. The incorporation of MOF-5 has offered increased hydrophilicity of polymeric membranes and is confirmed by the $70 \%, 80.58 \%$ and $46.47 \%$ improvement in permeability for CA, PES and PVDF membranes respectively with $0.5 \mathrm{wt}$. \% loading of MOF-

5. The MOF-5 incorporated polymeric membranes (PES/MOF-5, CA/MOF-5, and 
PVDF/MOF-5) has higher rejection efficiency of $\mathrm{Cu}$ (II) and $\mathrm{Co}$ (II) ions compared to neat polymeric membranes.

\section{References}

[1] Fu, F.; Wang, Q. (2011) Removal of heavy metal ions from wastewaters: a review.

[2] Bakhtiari, N.; Azizian, S. (2015) Adsorption of copper ion from aqueous solution by

[3] Babel, S.; Kurniawan, T. A. (2004) Cr (VI) removal from synthetic wastewater using coconut shell charcoal and commercial activated carbon modified with oxidizing agents and/or chitosan. Chemosphere, 54: 951-967.

[4] Wan Ngah, W.S.; Hanafiah, M.A.K.M. (2008) Removal of heavy metal ions from wastewater by chemically modified plant wastes as adsorbents: A review. Bioresource Technology, 99: 3935-3948.

[5] Al-Saydeh, S. A.; El-Naas, M. H.; Zaidi, S. J. (2017) Copper removal from industrial wastewater: A comprehensive review. Journal of Industrial and Engineering Chemistry, 56: 35-44.

[6] Al-Rashdi, B.; Somerfield, C.; Hilal, N. (2011) Heavy metals removal using adsorption and nanofiltration techniques. Separation \& Purification Reviews, 40 (3): 209-259.

[7] Qdaisa, H.A.; Moussa, H. (2004) Removal of heavy metals from wastewater by membrane processes: a comparative study. Desalination, 164: 105-110. 
[8] Li, X.; Liu, Y.; Wang, J.; Gascon, J.; Li, J.; Van der Bruggen, B. (2017) Metal- organic frameworks based membranes for liquid separation. Chemical Society Reviews, 46: $7124-7144$.

[9] Echaide-Górriz, C.; Sorribas, S.; Téllez, C.; Coronas, J. (2016) MOF nanoparticles of MIL-68 (Al), MIL-101 (Cr) and ZIF-11 for thin film nanocomposite organic solvent nanofiltration membranes. RSC Advances, 6 (93): 90417-90426.

[10] Wang, X.; Zhai, L.; Wang, Y.; Li, R.; Gu, X.; Yuan, Y.D.; Qian, Y.; Hu, Z.; Zhao, D. (2017) Improving Water-Treatment Performance of Zirconium Metal-Organic Framework Membranes by Post synthetic Defect Healing. ACS applied materials \& interfaces, 9 (43): 37848-37855.

[11] Ma, J.; Guo, X.; Ying, Y.; Liu, D.; Zhong, C. (2017) Composite ultrafiltration membrane tailored by MOF@ GO with highly improved water purification performance. Chemical Engineering Journal, 313: 890-898.

[12] Rivera, J.M.; Rincón, S.; Ben Youssef, C.; Zepeda, A. (2016) Highly Efficient Adsorption of Aqueous $\mathrm{Pb}$ (II) with Mesoporous Metal-Organic Framework-5: An Equilibrium and Kinetic Study. Journal of Nanomaterials, 2016.

[13] Ming, Y.; Purewal, J.; Yang, J.; Xu, C.; Soltis, R.; Warner, J.; Veenstra, M.; Gaab, M.; Müller, U.; Siegel, D.J. (2015) Kinetic stability of MOF-5 in humid environments: impact of powder densification, humidity level, and exposure time. Langmuir, 31 (17): 4988-4995.

[14] Mahdi, E.M.; Tan, J.C. (2016) Dynamic molecular interactions between polyurethane and ZIF-8 in a polymer-MOF nanocomposite: Microstructural, thermo-mechanical and viscoelastic effects. Polymer, 97: 31-43. 
[15] Mueller, U.; Schubert, M.; Teich, F.; Puetter, H.; Schierle-Arndt, K.; Pastre, J. (2006) Metal-organic frameworks prospective industrial applications. Journal of Materials Chemistry, 16: 626-636.

[16] Jonsson, G.; Boesen, C.E. (1977) Concentration polarization in a reverse osmosis test cell. Desalination, 21 (1): 1-10.

[17] Iswarya, N.; Kumar, M.G.; Rajan, K.S.; Balaguru, R.J.B. (2012) Synthesis, characterization and adsorption capability of MOF-5. Asian Journal of Scientific Research, 5 (4): 247-254.

[18] Abdel-Karim, A.; Gad-Allah, T.A.; El-Kalliny, A.S.; Ahmed, S.I.; Souaya, E.R.; Badawy, M.I.; Ulbricht, M. (2017) Fabrication of modified polyethersulfone membranes for wastewater treatment by submerged membrane bioreactor. Separation and Purification Technology, 175: 36-46.

[19] Rodrigues Filho, G.; Monteiro, D.S.; da Silva Meireles, C., de Assunção, R.M.N.; Cerqueira, D.A.; Barud, H.S.; Ribeiro, S.J.; Messadeq, Y. (2008) Synthesis and characterization of cellulose acetate produced from recycled newspaper. Carbohydrate Polymers, 73 (1): 74-82.

[20] Zhao, C.; Xu, X.; Chen, J.; Yang, F. (2013) Effect of graphene oxide concentration on the morphologies and antifouling properties of PVDF ultrafiltration membranes. Journal of Environmental Chemical Engineering, 1 (3): 349-354.

[21] Tirmizi, S.A.; Badshah, A.; Ammad, H.M.; Jawad, M.; Abbas, S.M.; Rana, U.A.; Khan, S.U.D. (2018) Synthesis of highly stable MOF-5@ MWCNTs nanocomposite with improved hydrophobic properties. Arabian Journal of Chemistry, 11 (1): 26-33.

[22] Abedini, R.; Mousavi, S. M.; Aminzadeh, R. (2011) A novel cellulose acetate (CA) membrane using $\mathrm{TiO}_{2}$ nanoparticles: Preparation, characterization and permeation study. Desalination, 277: 40-45. 
[23] Boussu, K. ; Van der Bruggen, B.; Volodin, A.; Van Haesendonck, C.V.; Delcour, J.A.; Van der Meeren, P.; Vandecasteele, C. (2006) Characterization of commercial Nanofiltration membranes and comparison with self-made polyethersulfone membranes. Desalination, 191: 245-253.

[24] Nikooe, N.; Saljoughi, E. (2017) Preparation and characterization of novel PVDF Nanofiltration membranes with hydrophilic property for filtration of dye aqueous solution. Applied Surface Science, 413: 41-49.

[25] Shen, L.; Bian, X.; Lu, X.; Shi, L.; Liu, Z.; Chen, L.; Hou, Z.; Fan, K. (2012) Preparation and characterization of $\mathrm{ZnO} /$ polyethersulfone (PES) hybrid membranes. Desalination, 293: 21-29.

[26] Rahimpour, A.; Jahanshahi, M.; Khalili, S.; Mollahosseini, A.; Zirepour, A.; Rajaeian, B. (2012) Novel functionalized carbon nanotubes for improving the surface properties and performance of polyethersulfone (PES) membrane. Desalination, 286: 99-107.

[27] Wua, G.; Gan, S.; Cui, L.; Xu, Y. (2008) Preparation and characterization of PES/TiO2 composite membranes. Applied Surface Science, 254: 7080-7086.

[28] Sotto, A.; Orcajo, G.; Arsuaga, J.M.; Calleja, G.; Landaburu-Aguirre, J. (2015) Preparation and characterization of MOF-PES ultrafiltration membranes. Journal of Applied Polymer Science, 132 (21).

[29] Zeng, G.; Ye, Z.; Hea, Y.; Yang, Xi; Maa, J.; Shi, H.; Feng, Z. (2017) Application of dopamine-modified halloysite nanotubes/PVDF blend membranes for direct dyes removal from wastewater. Chemical Engineering Journal, 323: 572-583. 
439 Table caption

440 Table 1. Composition of casting solution for the preparation of composite membranes

441 Table 2. Mass transfer coefficient (K) and diffusion coefficient (D)

442 Table 3. Porosity and mean pore radius of membranes

443 Table 4. Contact angle measurement

444 Table 5. Membrane resistance and pure water flux

445 Table $6 . \mathrm{Cu}$ (II) rejection of membranes

446 Table 7. Co (II) rejection of membranes

447

448

449

450

451

452

453

454

455

456

457

458

459

460

461

462

463 
TABLES

465

\begin{tabular}{lcccc}
\hline Membrane type & \multicolumn{3}{c}{ Composition of casting solutions } & 466 \\
& Polymer & MOF-5 & DMF solvent & 467 \\
& $(\mathbf{g})$ & $(\mathbf{g})$ & $(\mathbf{m l})$ & 468 \\
& 4.375 & - & 21.7 & 469 \\
\hline Neat PES & 4.353 & 0.022 & 21.7 & 470 \\
PES+ 0.5\% MOF-5 & 4.375 & - & 21.7 & 471 \\
Neat PVDF & 4.353 & 0.022 & 21.7 & 473 \\
PVDF+0.5\% MOF-5 & 4.375 & - & 21.7 & 474 \\
Neat CA & 4.353 & 0.022 & 21.7 & 475 \\
CA+ 0.5\% MOF-5 & & & & 476
\end{tabular}

480

\begin{tabular}{ccc}
\hline Feed solution & K & D \\
\hline Copper solution & $5.78 \times 10^{-5} \mathrm{~m} / \mathrm{s}$ & $4.335 \times 10^{-9} \mathrm{~m}^{2} / \mathrm{s}$ \\
Cobalt solution & $4.22 \times 10^{-5} \mathrm{~m} / \mathrm{s}$ & $4.182 \times 10^{-9} \mathrm{~m}^{2} / \mathrm{s} 482$
\end{tabular}

483 


\begin{tabular}{ccc}
\hline Membranes & Porosity (\%) & Mean Pore radius (nm) \\
\hline PES & 70.50 & 5.62 \\
CA & 78.94 & 6.97 \\
CA/MOF-5 & 72.50 & 5.57 \\
PVDF & 81.26 & 9.09 \\
PVDF/MOF-5 & 65.32 & 3.92 \\
\end{tabular}

488

489 Table 3. Porosity and mean pore radius of membranes

490

\begin{tabular}{cc}
\hline Membranes & Contact Angle $\left(^{\circ}\right)$ \\
\hline PES/MOF-5 & 76.42 \\
CA/MOF-5 & 70.68 \\
PVDF/MOF-5 & 72.975 \\
PES & 86.075 \\
CA & 75.03 \\
PVDF & 80.47 \\
\hline
\end{tabular}

491

492

Table 4. Contact angle measurement

493

494

495 


\begin{tabular}{|c|c|c|}
\hline Membrane Type & $\begin{array}{l}\text { Membranes } \\
\text { Resistance, } R_{m}\left(m^{-1}\right)\end{array}$ & $\begin{array}{l}\text { Pure water flux } \\
\left(\mathrm{L} / \mathrm{m}^{2} \mathrm{hr}\right)\end{array}$ \\
\hline PES & $13 \times 10^{13}$ & $29.52 \pm 1.6$ \\
\hline PES/MOF-5 & $7.4 \times 10^{13}$ & $53.31 \pm 1.6$ \\
\hline $\mathrm{CA}$ & $9.6 \times 10^{13}$ & $41.01 \pm 1.2$ \\
\hline CA/MOF-5 & $5.6 \times 10^{13}$ & $69.72 \pm 1.4$ \\
\hline PVDF & $17 \times 10^{13}$ & $22.96 \pm 1.4$ \\
\hline PVDF/MOF-5 & $11 \times 10^{13}$ & $33.63 \pm 1.2$ \\
\hline
\end{tabular}

496

497

Table 5. Membrane resistance and pure water flux

\begin{tabular}{ccccc}
\hline Membrane Type & $\mathrm{C}_{\mathrm{m}}(\mathrm{ppm})$ & \multicolumn{2}{c}{ Rejection percentage (\%) } & 498 \\
& & $\mathrm{R}_{\mathrm{obs}}$ & $\mathrm{R}_{\text {real }}$ & 499 \\
\hline PES & 1178.14 & 30.5 & 35.35 & 500 \\
PES/MOF-5 & 1075.12 & 51.4 & 58.74 & \\
CA & 1111.97 & 50.8 & 52.39 & 501 \\
CA/MOF-5 & 1033.57 & 53.3 & 58.00 & 502 \\
PVDF & 1072.63 & 52.3 & 55.52 & 503 \\
PVDF/MOF-5 & 1039.91 & 54.3 & 56.05 & \\
& & & & 504 \\
\hline
\end{tabular}

505

Table 6. Cu (II) rejection of membranes

506

507

508 


\begin{tabular}{cccc}
\hline Membranes type & $\mathrm{C}_{\mathrm{m}}(\mathrm{ppm})$ & \multicolumn{2}{c}{ Rejection Efficiency \% } \\
& & $\mathrm{R}_{\text {obs }}(\%)$ & $\mathrm{R}_{\text {real }}(\%)$ \\
\hline PES & 1084.29 & 58.35 & 61.58 \\
PES/MOF-5 & 1225.31 & 74.40 & 79.10 \\
CA & 1079.60 & 45.30 & 49.34 \\
CA/MOF-5 & 1353.49 & 77.0 & 83.00 \\
PVDF & 1040.16 & 41.8 & 44.04 \\
PVDF/MOF-5 & 1116.93 & 64.20 & 67.94
\end{tabular}

510

511

Table 7. Co (II) rejection of membranes

512

513

514

515

516

517

518

519

520

521 


\section{Figure caption}

524 Scheme. 1. Schematic representation of removal of heavy metal ions from aqueous solution by MOF-5 incorporated membranes Nanofiltration.

526 Figure 1. FTIR spectra of MOF-5

527 Figure 2. XRD image of MOF-5

528 Figure 3. SEM image of MOF-5

529 Figure 4. FT-IR spectra of MOF-5, neat and MOF-5 incorporated membranes

530 Figure 5. XRD analysis of MOF-5, neat and MOF-5 incorporated membranes

531 Figure 6. Cross-sectional view of (a) neat PES and (b) PES/MOF-5

532 Figure 7. Cross-sectional view of (c) neat CA and (d) CA/MOF-5

533 Figure 8. Cross-sectional Image of (e) neat PVDF and (f) PVDF/MOF-5

534 Figure 9. Pure water flux of membranes

535 Figure 10. Flux of copper feed solution for membranes

536 Figure 11. Flux of cobalt feed solution for membranes

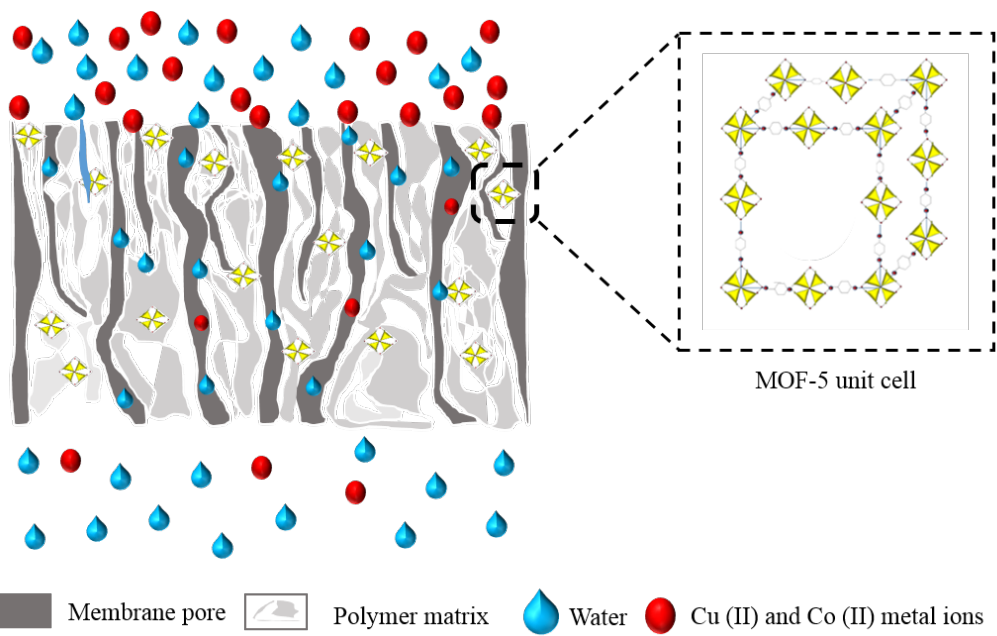

Scheme. 1. Schematic representation of removal of heavy metal ions from aqueous solution by MOF-5 incorporated membranes Nanofiltration. 


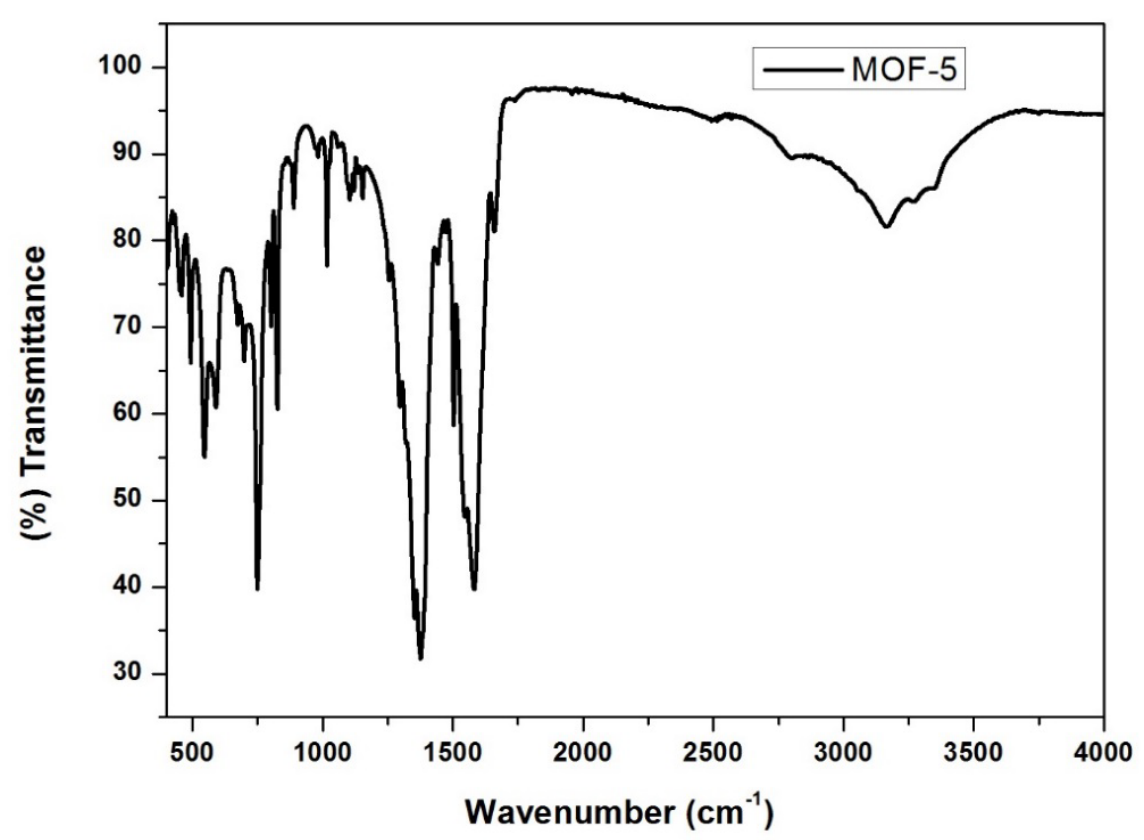

556

Figure 1. FTIR spectra of MOF-5

558

559

560

561

562

563

564

565

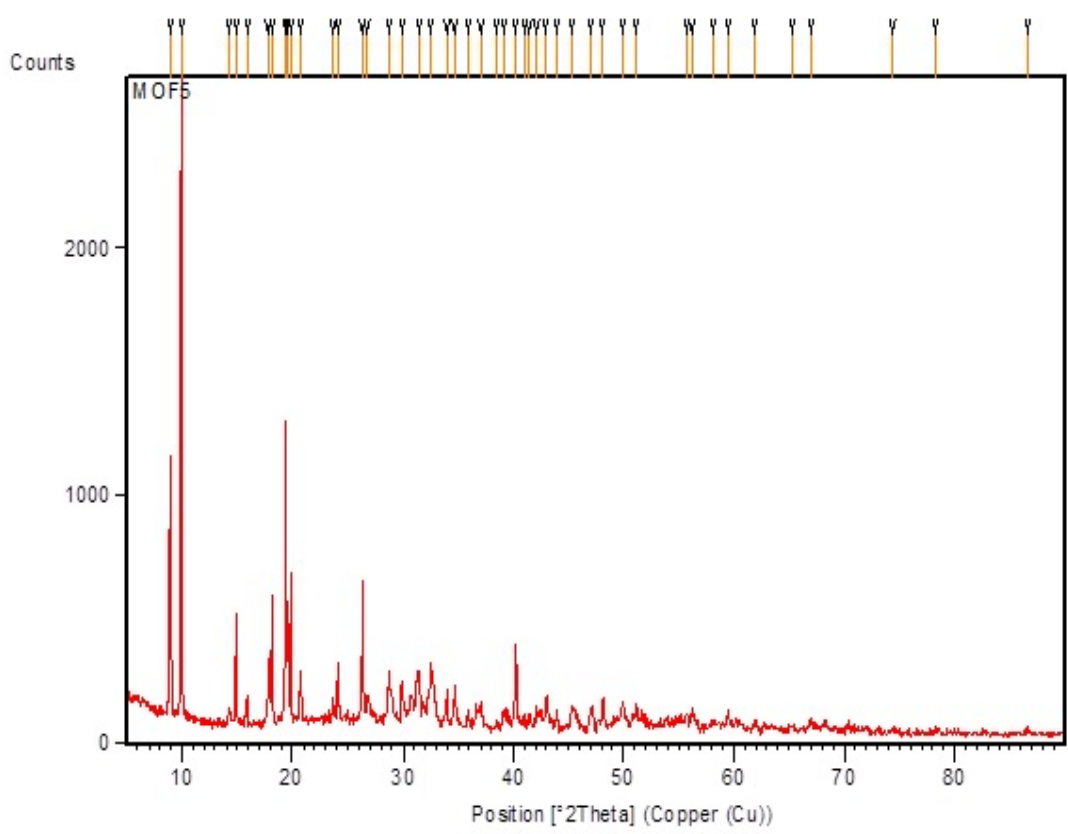

566

Figure 2. XRD image of MOF-5

567

568 

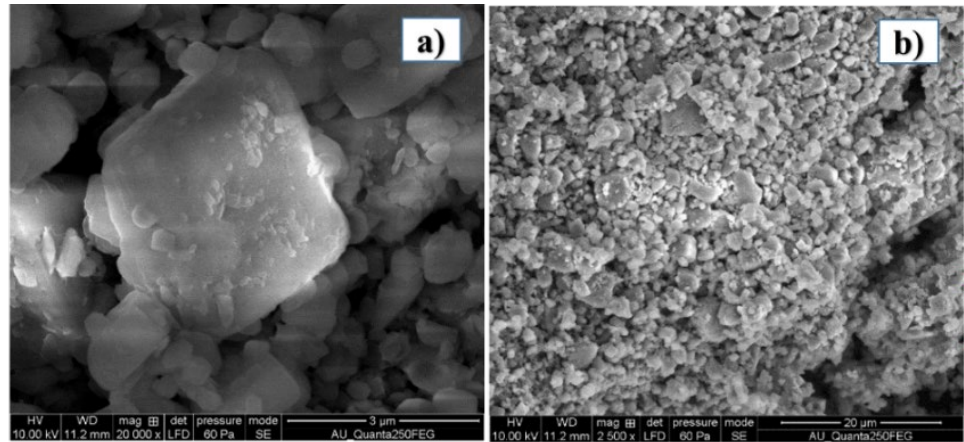

572

c)

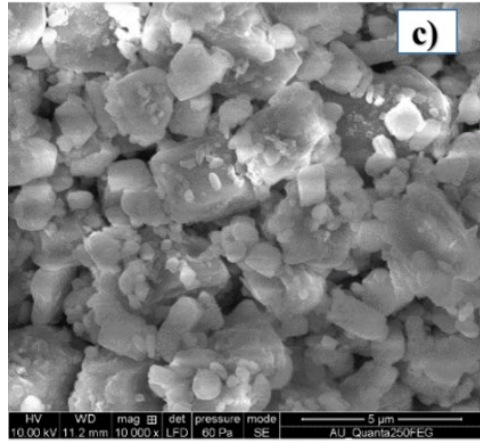

d)

574

575

576

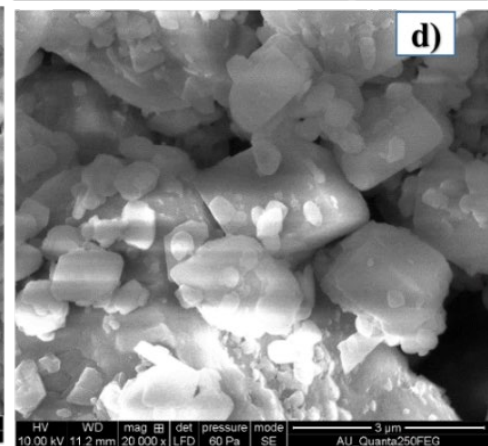

Figure 3. SEM image of MOF-5

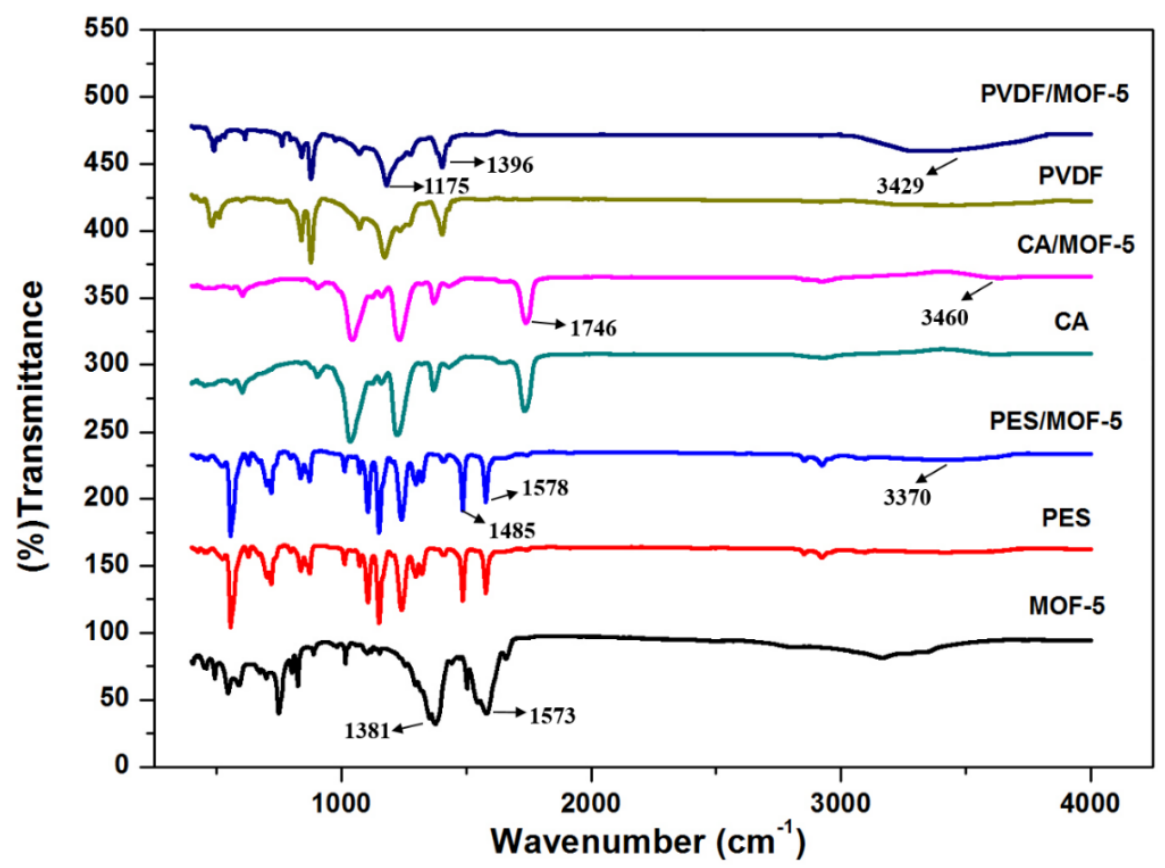

Figure 4. FT-IR spectra of MOF-5 and membranes 


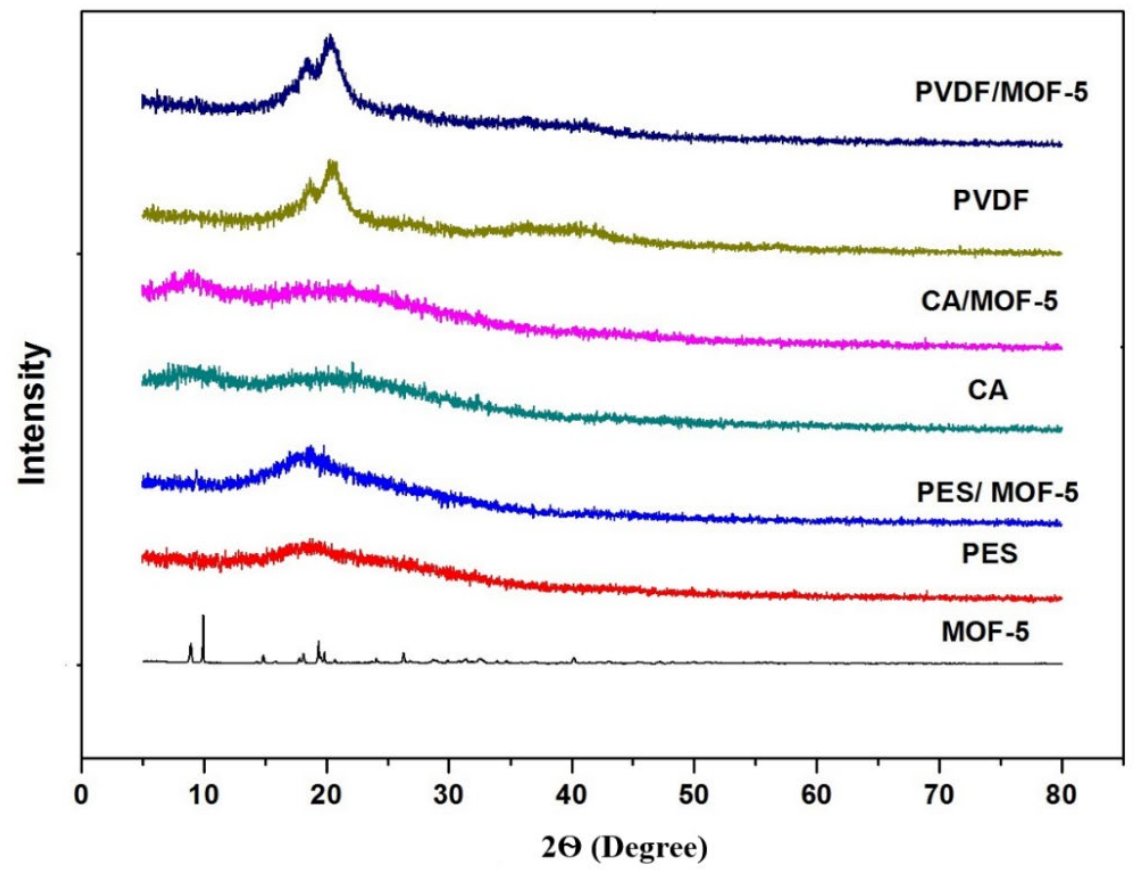
Figure 5. XRD analysis of MOF-5 and membranes
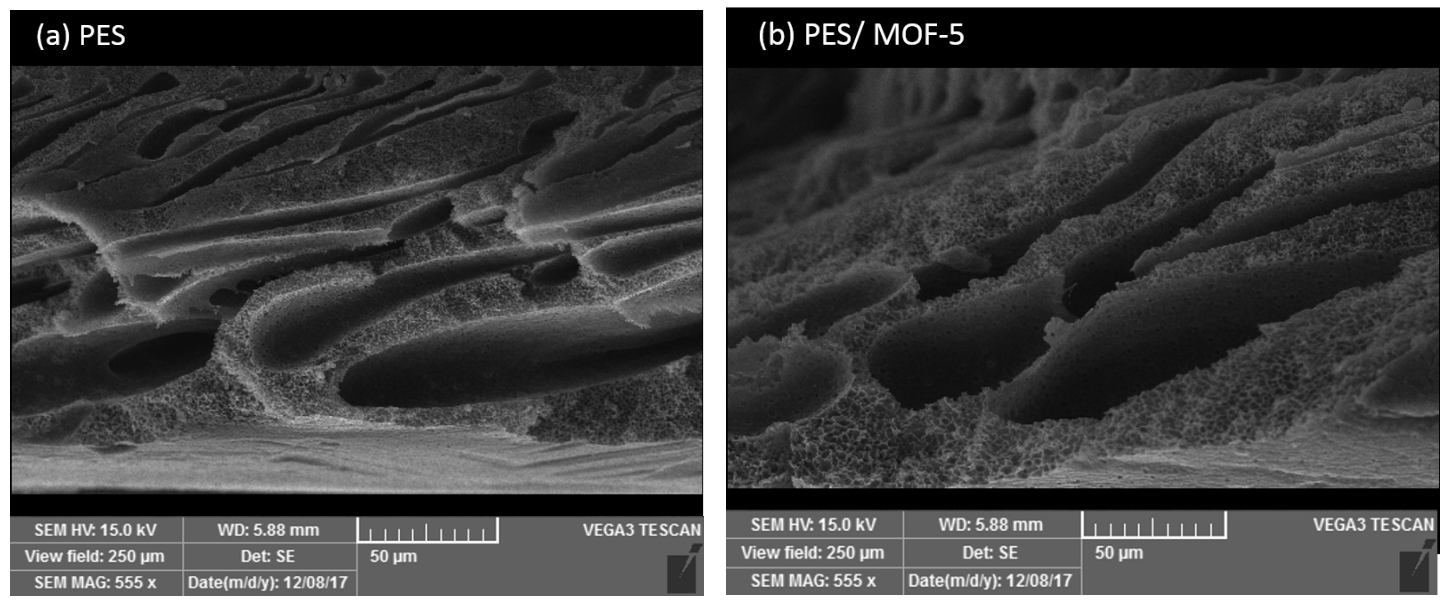

Figure 6. Cross-sectional view of (a) neat PES and (b) PES/MOF-5 

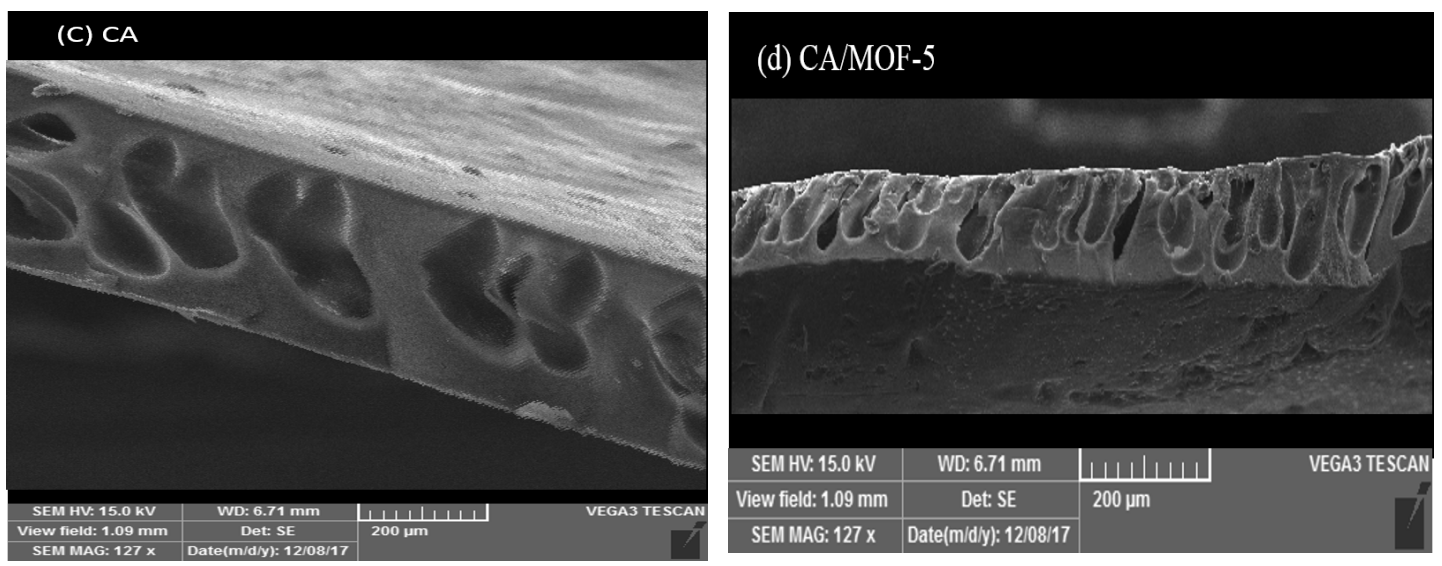

Figure 7. Cross-sectional view of (c) neat CA and (d) CA/MOF-5
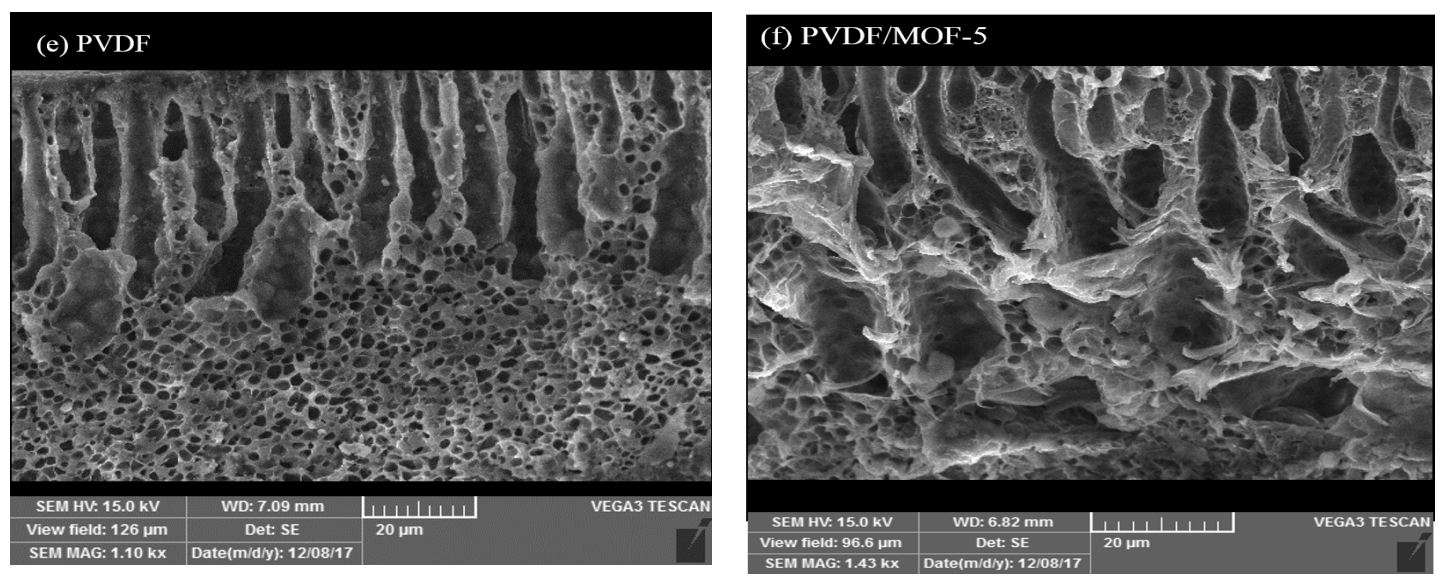

605

Figure 8. Cross-sectional Image of (e) neat PVDF and (f) PVDF/MOF-5

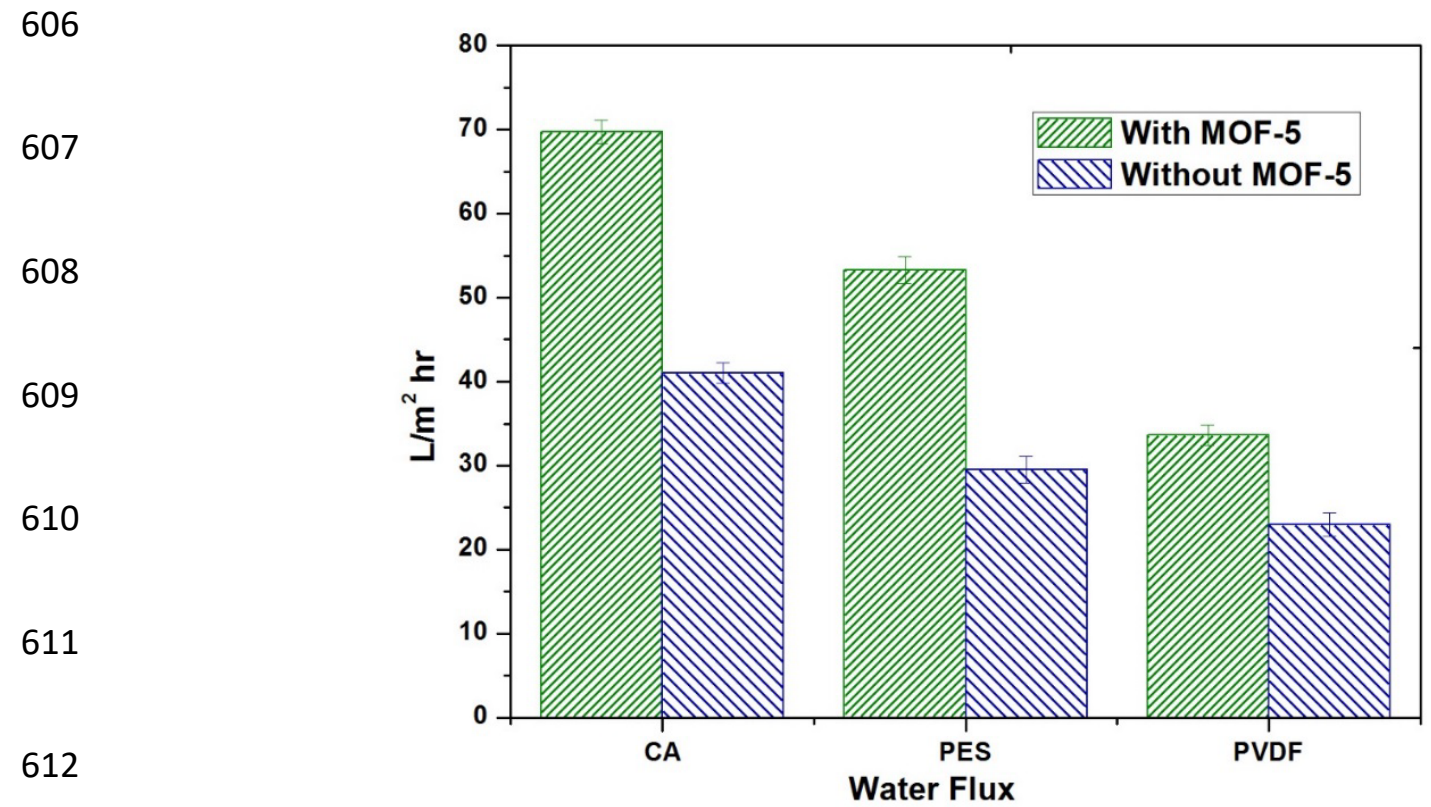

Figure 9. Pure water flux of membranes 


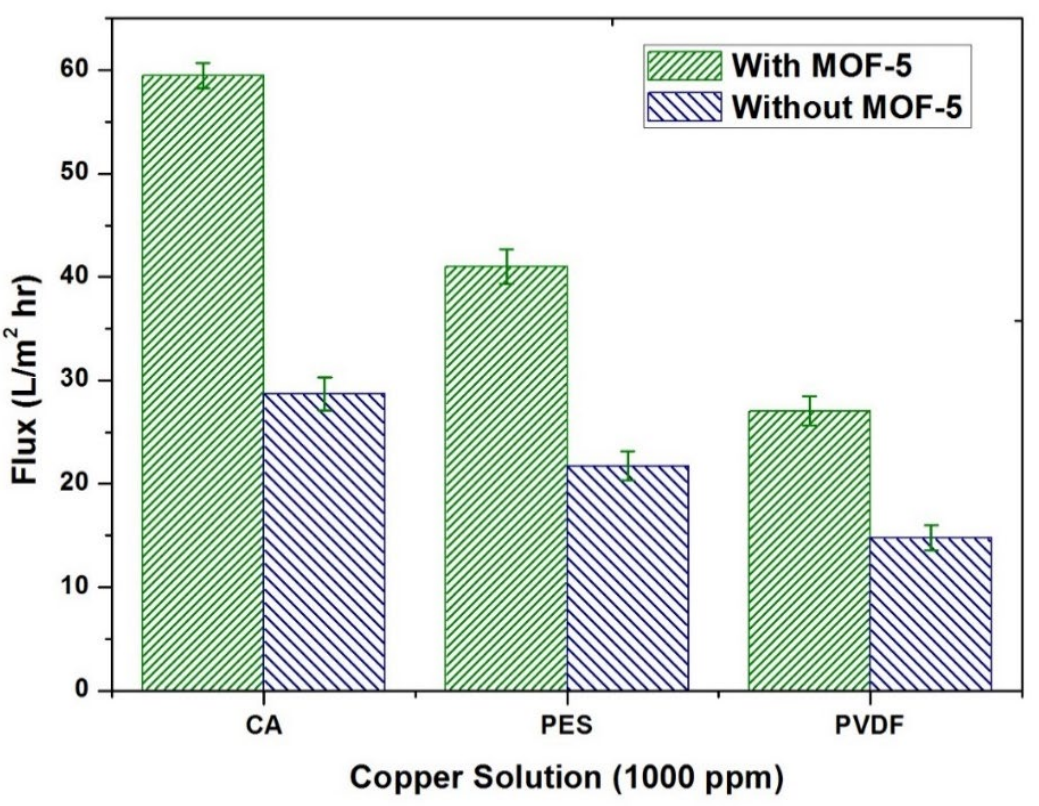

615

Figure 10. Flux of copper feed solution for membranes

\section{6}

617

618

619

620

621

622

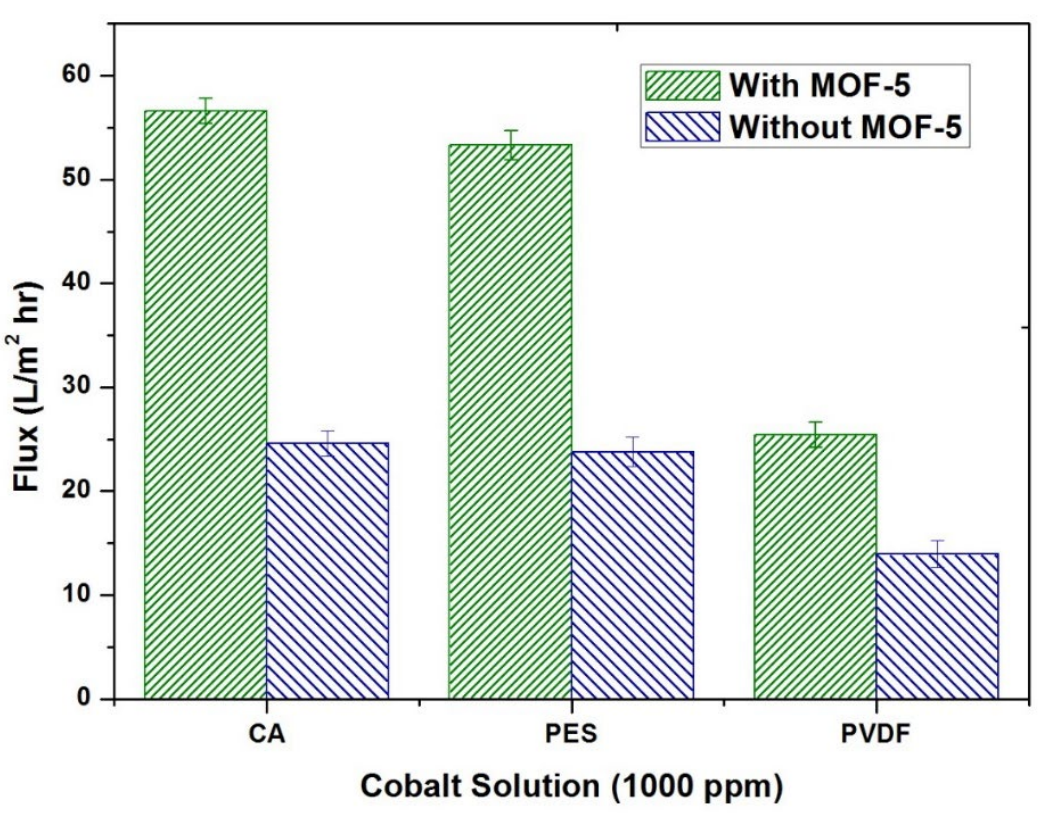

623

Figure 11. Flux of cobalt feed solution for membranes 